\title{
Quality of life assessment in patients with heart failure: validity of the German version of the generic EQ-5D-5 $\mathrm{L}^{\mathrm{TM}}$
}

\author{
Sigrid Boczor ${ }^{1 *}\left(\mathbb{D}\right.$, Anne Daubmann², Marion Eisele ${ }^{1}$, Eva Blozik $^{1}$ and Martin Scherer ${ }^{1}$
}

\begin{abstract}
Background: Chronic heart failure patients typically suffer from tremendous strain and are managed mainly in primary care. New care concepts adapted to the severity of heart failure are a challenge and need to consider health-related quality of life aspects. This is the first psychometric validation of the German EQ-5D-5L ${ }^{\mathrm{TM}}$ as a generic instrument for assessing health-related quality of life (HRQOL) in a primary care heart failure patient sample.

Methods: Confirmatory factor analysis (CFA) was performed on the baseline EQ-5D-5L' ${ }^{\mathrm{TM}}$ data from the RECODE-HF study (responses to all items from $n=3225$ of 3778 patients). Basic CFA models for HRQOL were calculated based on the EQ-5D-5 ${ }^{\mathrm{TM}}$ items using the maximum likelihood $(\mathrm{ML})$ and the asymptotic distribution-free method. In an extended CFA, physical activity and depression were added. The basic CFA ML model was verified for the reduced number of cases of the extended CFA model $(n=3064)$. In analyses of variance the association of the EQ-5D-5 $\mathrm{L}^{\mathrm{TM}}$ visual analogue scale (VAS) and both the German and the British EQ-5D-5 $\mathrm{L}^{\mathrm{TM}}$ crosswalk index with the SF-36 measure of general health were examined. The discriminant validity was analysed using Pearson's chi-squared tests applying the New York Heart Association classification, for the VAS and indices analyses of variance were calculated.

Results: In the basic CFA models the root mean square error of approximation was 0.095 with the ML method, and 0.081 with the asymptotic distribution-free method (Comparative Fit Index $>0.90$ for both). Physical activity and depression were confirmed as influential factors in the extended model. The VAS and indices were strongly associated with the SF-36 measure of general health (partial eta-squared 0.525/0.454/0.481; all $p<0.001 ; n=3155 / 3210 / 3210$, respectively), also for physical activity and depression when included together (partial eta-squared 0.050, 0.200/0.047, $0.213 / 0.051$ and 0.270 ; all $p<0.001 ; n=3015 / n=3064 / n=3064$, respectively). The discriminant validity analyses showed $p$-values $<0.001$ and small to moderate effect sizes for all EQ-5D-5 $\mathrm{L}^{\mathrm{TM}}$ items. Analyses of variance demonstrated moderate effect sizes for the VAS and indices (0.067/0.087/0.084; all $p<0.001 ; n=3110 / 3171 / 3171)$.
\end{abstract}

Conclusion: The German EQ-5D-5 $\mathrm{L}^{\mathrm{TM}}$ is a suitable method for assessing HRQOL in heart failure patients.

Keywords: Heart failure, Quality of life, EQ-5D-5L, Confirmatory factor analysis, Construct analysis, Discriminant validity

\section{Background}

Chronic heart failure (CHF) is a common disease managed mainly in primary care that typically places tremendous strain on patients in all developed countries [1-3].

\footnotetext{
* Correspondence: s.boczor@uke.de

This study was performed at the Department of General Practice / Primary Care, Center for Psychosocial Medicine, University Medical Center HamburgEppendorf, Germany, Martinistraße 52, 20246, Hamburg, Germany

'Department of General Practice / Primary Care, Center for Psychosocial Medicine, University Medical Center Hamburg-Eppendorf, Germany, Martinistraße 52, 20246 Hamburg, Germany

Full list of author information is available at the end of the article
}

The New York Heart Association (NYHA) classification is the standard approach to assessing severity; guidelines for the management of heart failure patients include the goal of improving health-related quality of life (HRQOL) [4-6]. Maximising HRQOL while treating CHF is still a major challenge $[3,6-9]$. In primary care, CHF patients are in need of new concepts adapted to the severity of their disease that consider life expectancy and HRQOL. Patients with CHF mostly experience symptoms such as dyspnoea, fatigue, sleep disorders, and ankle oedema [10]. Several treatment strategies have been examined in

(c) The Author(s). 2019 Open Access This article is distributed under the terms of the Creative Commons Attribution 4.0 International License (http://creativecommons.org/licenses/by/4.0/), which permits unrestricted use, distribution, and 
the past decade with a view to improving HRQOL in CHF patients based on different influential factors. Using the Kansas City Cardiomyopathy Questionnaire (KCCQ), Whellan et al. 2007 identified physical exercise, the primary study objective in their randomised controlled HFACTION trial, as a 'modest but statistically significant' factor that influences HRQOL among CHF patients [11]. While this finding supported the pursuit of physical exercise in such patients [4-6], additional efforts were still necessary with respect to improving HRQOL, such as collecting sufficient data on end-of-life preferences related to HRQOL among elderly CHF patients [3, 8]. Stamp et al. 2014 studied CHF patients with NYHA class II and III in the context of family life, focusing specifically on patient autonomy - an aspect that so far has received little attention in studies [12].

Several treatment options are currently available to CHF patients which target either symptoms or prognosis, or both. It is questionable whether reduced mortality is the primary aim of treatment for CHF patients or whether patients would rather benefit from symptomatic relief, i.e. a better HRQOL [8]. Taking the baseline data of the TIME-CHF trial, Brunner-La Rocca et al. examined whether elderly CHF patients would prefer an improved HRQOL (e.g. no symptoms) over longevity [8]. They found that $74 \%$ of patients with a high burden of comorbidities were unwilling whereas $26 \%$ were willing to trade survival time for improved HRQOL [8]. The patients willing to trade longevity for quality of life were typically older, female, and living alone, and had a higher disease burden from CHF and a lower HRQOL as assessed by the Minnesota Living with Heart Failure questionnaire [8].

In 2012, Hoekstra et al. reported that most studies of CHF patients prefer to use a disease-specific rather than generic questionnaire to assess HRQOL [13]. However, a generic questionnaire permits HRQOL to be compared between patients with different diseases and therefore can add great value to research. Some larger, more specific questionnaires are available with which to evaluate the burden of heart failure $[8,14]$ but their completion demands a high level of willingness on the part of patients, which in the primary care setting is especially difficult. One of the world's most widely used instruments for assessing HRQOL is the short generic EQ- $5 \mathrm{D}^{\circ}$, which is available in more than 130 languages [15-17]. Clouth et al. tested the construct validity of the former 3-level German version of the EQ-5D in CHF patients [16]. They found mixed evidence, with a low explained variance component and low factor loading on the question of anxiety and depression. The English version of the new 5-level EQ-5D ${ }^{\circ}$ (EQ-5D-5L $\left.{ }^{\mathrm{Tm}}\right)$ introduced in 2011 [18] has been validated in patients with cardiovascular disease, respiratory disease, depression, diabetes, liver disease, personality disorders, arthritis, and stroke [19]. However, worldwide validation of the EQ-5D-5L ${ }^{\mathrm{mm}}$, which expands the descriptive system response scale from three to five categories, is still ongoing. The EQ-5D-5 $\mathrm{L}^{\mathrm{mi}}$ has not yet been validated for CHF patients. In general practice in particular, its time-saving application in the care of CHF patients should help to assess and thus improve HRQOL. In the research setting, moreover, use of the very short EQ-5D-5L ${ }^{\mathrm{ma}}$ could reduce the response burden. The goal of this research project was to validate the German version of the EQ-5D-5 $\mathrm{L}^{\mathrm{mm}}$ for CHF patients.

\section{Key elements of the EQ-5D-5 $\mathrm{T}^{\mathrm{Tm}}$}

The EQ-5D-5L $\mathrm{L}^{\mathrm{Th}}$ consists of five dimensions (mobility, self-care, usual activities, pain/discomfort and anxiety/ depression) related to a patient's well-being (descriptive system; I1-I5). Each item can be answered on a 5-point scale (no/slight/moderate/severe/extreme problems). The answers to the five dimensions can be combined in a 5-digit number describing the patient's state of health. Using a population-specific value set or EuroQol Groups' crosswalk calculation [20], this number can be converted into an EQ index value which is commonly used to calculate quality-adjusted life years. The second patient selfrating measure is the EQ visual analogue scale (EQ VAS), whereby the well-being of the patient is rated with a number ranging from 0 (worst health the patient can imagine) to 100 (best health the patient can imagine). The EQ-5D parameters analysed in this project comprised the aforementioned items, the EQ VAS, and the German and the British crosswalk index of the EQ-5D-5 $\mathrm{L}^{\mathrm{mm}}$.

\section{Methods}

To determine the suitability of the EQ-5D-5L $\mathrm{L}^{\mathrm{Tm}}$ for CHF patients, we evaluated its psychometric features using baseline data from the observational RECODE-HF study that has been described in detail in the study protocol and elsewhere [21-24]. In brief, ethical clearance has been granted by two local ethics committees. Patients with CHF had been recruited via German primary care practices between 2012 and 2014. Of the 4420 general practitioners (GP) invited, 293 finally participated. Patient inclusion criteria had been an informed consent, an age of at least 18 years, a CHF diagnosis documented within the last 5 years at the GP, and at the least one GP contact within the last 6 months; exclusion criteria were dementia and CHF patients who were not regular patients of the participating GP practice. Of $13,830 \mathrm{pa}$ tients invited to participate in the RECODE-HF study, 5385 consented, and 4909 sent back the baseline questionnaire. The patient's GP was interviewed by phone particularly regarding the patient's comorbidities. The comorbidities of $3387 \mathrm{CHF}$ patients were assessed. Of these patients the study population of the present 
analyses included all patients who answered the EQ-5D$5 \mathrm{~L}^{\mathrm{Tu}}$ descriptive system in full, i.e. $n=3225$ patients, as well as thereof $n=3064 / n=3210 / n=3171$ patients where the adjustment variables physical activity and psychosocial distress/the SF-36 general health status/the NYHA class were available, respectively. As the indices were calculated from the fully answered five items the sample size here was identical. Correspondingly, analyses of variance of the EQ-5D-5 $\mathrm{L}^{\mathrm{m}}$ VAS were based on patients with full data sets, i.e. the samples comprised of those patients who fully answered the five items and also answered the visual analogue scale as well as the included factors (physical activity and psychosocial distress: $n=3015$; SF-36 general health status: $n=3155$; NYHA class: $n=3110$, respectively) as no data imputation algorithm was applied.

\section{Statistical analyses}

Patient characteristics are presented as mean and standard deviation (SD) in the case of continuous data, and absolute and relative frequencies in the case of categorical data. Charlson's Comorbidity Index was used to classify comorbid conditions [21]. CHF patients with co-morbid conditions were identified by Charlson's comorbidities and compared to CHF only patients. On the EQ-5D-5L $\mathrm{L}^{\mathrm{ma}}$ items Pearson's chi-squared tests and for the EQ-5D-5L $\mathrm{L}^{\mathrm{max}}$ VAS and indices T-Tests were performed, respectively. The patients'age was differentiated by quartiles and the EQ$5 \mathrm{D}-5 \mathrm{~L}^{\mathrm{m}}$ items were analysed by Pearson's chi-squared tests, and for the EQ-5D-5 $\mathrm{L}^{\mathrm{ma}} \mathrm{VAS}$ and indices analyses of variance (ANOVA) was performed, respectively.

\section{Construct validity}

A confirmatory factor analysis (CFA) model was used to obtain evidence of one-dimensionality of the EQ-5D-5 $\mathrm{L}^{\mathrm{mm}}$ items for mapping HRQOL in CHF patients [16]. Because of doubts about the multivariate normality, in addition to the maximum likelihood (ML) method the asymptotic distribution-free (ADF) method was applied to estimate the parameters [22, 23], and the results were compared. The estimates found to be quite similar (see Table 2), and this fact suggested that the multivariate normal distribution assumption was justified. Local fit measures (explained variance; average variance; correlation coefficient; standardised regression coefficient; factor reliability) [24, 25] and global fit measures (chi-squared statistic; root mean square error of approximation, RMSEA; Comparative Fit Index, CFI; Tucker-Lewis Index, TLI) [22, 25-27] were calculated.

To analyse the association with the question of general health on the SF-36, by rating general health on a fivepoint scale from 'excellent' to 'poor', analyses of variance (ANOVA) was performed for the EQ-5D-5L ${ }^{\text {Tx }}$ VAS and indices. The $P$-value and effect size (partial eta-squared) are presented; effect sizes were interpreted in accordance with Cohen [28, 29].

\section{Extended CFA}

The CFA model was extended by simultaneously adding a physical activity score and psychosocial distress assessment. In several studies, both parameters have been found to essentially influence HRQOL in CHF patients $[5,30,31]$. Psychosocial distress was classified according to a hierarchical algorithm [32], considering the Patient Health Questionnaire depression subscale (PHQ-9) [33-35], the Hospital Anxiety and Depression Scales (HADS-A and HADS-D) [36, 37], and the PatientReported Outcomes Measurement Information System $\left(\right.$ PROMIS $\left.^{\circ}\right)$ depression and anxiety items [38, 39]. Parameter estimates are presented. To ensure reliable interpretation, the basic CFA ML model was recalculated with a reduced sample size due to the lower number of cases resulting from the model, including influential factors. The impact of physical activity and psychosocial distress on the EQ VAS measurement and indices was analysed using ANOVA. Physical activity and psychosocial distress were simultaneously added to each model. Model parameters are described.

CFA was performed with IBM SPSS Amos 23.0.0. Factor reliability and the average proportion of variance were calculated in accordance with M. Wirtz 2004 [24]. IBM SPSS Statistics 23.0.0.2 was used for all other calculations.

\section{Internal consistency reliability}

Cronbach's coefficient alpha is given for the EQ-5D-5L $\mathrm{L}^{\mathrm{m}}$ items, as a typically reported measure for associations between multi-item scales. A limit of at least 0.90 for individual use was applied [40].

\section{Discriminant validity}

Pearson's chi-squared tests were performed on the EQ$5 \mathrm{D}-5 \mathrm{~L}^{\mathrm{Tw}}$ items to examine the distribution of patients into the categories of heart failure as classified by the NYHA categories, the standard criterion for CHF severity [4-6]. The $p$-value is given, along with the Pearson correlation coefficient (interpreted as effect size after Cohen). ANOVA was performed to analyse the EQ-5D$5 \mathrm{~L}^{\mathrm{m}}$ VAS and indices and describe the association with the NYHA categories. The $P$-value and partial etasquared are given.

\section{Results}

Of all 3387 patients of the RECODE-HF study [32], 95\% $(n=3225)$ completed the EQ-5D-5 $\mathrm{L}^{\text {tw }}$ descriptive system in full; of these, 98\% $(n=3164)$ also completed the EQ$5 \mathrm{D}-5 \mathrm{~L}^{\mathrm{Tm}}$ VAS. Patient characteristics are listed in Table 1. The mean \pm SD age of the patients was $74 \pm 10$ years, while the proportion of at least 80 -year-olds was almost 
Table 1 Baseline characteristics including comorbidities with prevalence greater than 20\% in the patient sample

\begin{tabular}{|c|c|}
\hline & $\begin{array}{l}\text { All patients } \\
(n=3225)\end{array}$ \\
\hline Female gender & $1454(45.1 \%)$ \\
\hline Age (years) & $73.9 \pm 10.2$ \\
\hline \multicolumn{2}{|l|}{ Education level (CASMIN) } \\
\hline Primary & $2040(63.3 \%)$ \\
\hline Secondary & $847(26.3 \%)$ \\
\hline Tertiary & $275(8.5 \%)$ \\
\hline \multicolumn{2}{|l|}{ Occupational status } \\
\hline Employed & $233(7.2 \%)$ \\
\hline Not employed & $2931(90.9 \%)$ \\
\hline \multicolumn{2}{|l|}{ Living situation } \\
\hline Living alone & $970(30.1 \%)$ \\
\hline Together with others in private household & $2123(65.8 \%)$ \\
\hline Living in an institution & $62(1.9 \%)$ \\
\hline \multicolumn{2}{|l|}{ NYHA classification } \\
\hline Class 1 & 775 (24.0\%) \\
\hline Class II & $1588(49.2 \%)$ \\
\hline Class III & $721(22.4 \%)$ \\
\hline Class IV & $87(2.7 \%)$ \\
\hline Missing & $54(1.7 \%)$ \\
\hline \multicolumn{2}{|l|}{ Psychosocial distress } \\
\hline No psychological disorder & $1514(46.9 \%)$ \\
\hline $\begin{array}{l}\text { Depression/depressive symptomatology/ } \\
\text { adjustment disorder likely }\end{array}$ & $546(16.9 \%)$ \\
\hline Anxiety/anxiety disorder possible & $370(11.5 \%)$ \\
\hline No psychological disorder likely & $658(20.4 \%)$ \\
\hline None of these criteria applicable & $137(4.2 \%)$ \\
\hline $\begin{array}{l}\text { Cardiac decompensation/congestive heart failure } \\
\text { with dyspnoea, improved during therapy }\end{array}$ & $2374(73.6 \%)$ \\
\hline Arterial hypertension & $1576(48.9 \%)$ \\
\hline Diabetes mellitus & $1221(37.9 \%)$ \\
\hline $\begin{array}{l}\text { Chronic ischaemic heart disease } \\
\text { (also after myocardial infarction, ischaemic } \\
\text { cardiomyopathy, angina pectoris) }\end{array}$ & $1153(35.8 \%)$ \\
\hline $\begin{array}{l}\text { Cardiac arrhythmias (atrioventricular block, } \\
\text { cardiac arrest, paroxysmal tachycardia, } \\
\text { atrial fibrillation) }\end{array}$ & $952(29.5 \%)$ \\
\hline Kidney disease & $913(28.3 \%)$ \\
\hline Dyslipidaemia & $763(23.7 \%)$ \\
\hline Myocardial infarction & $761(23.6 \%)$ \\
\hline $\begin{array}{l}\text { Asthma/chronic pulmonary disease with } \\
\text { pulmonary dyspnoea }\end{array}$ & 708 (22.0\%) \\
\hline
\end{tabular}

CASMIN, Comparative Analysis of Social Mobility in Industrial Nations (CASMIN criteria); NYHA, New York Heart Association; psychosocial distress classification according to hierarchical algorithm [32]; no more than $4 \%$ missing values per variable, except age and cardiac decompensation (both 5.5\%); arterial hypertension, chronic ischaemic heart disease, cardiac arrhythmias and dyslipidaemia were optionally assessed with the International Statistical Classification of Diseases and Related Health Problems (ICD)-10 codes
$30 \%$. Of all patients $45 \%$ were female. Almost $50 \%$ of the patients had mild symptoms and a comparable number marked or no CHF symptoms or limitations, whereas only $3 \%$ had severe problems even at rest. Elderly patients $\geq 80$ years accounted for almost $30 \%$. Half of the patients were physically active on a daily basis. A total of $28 \%$ tended towards depression/depressive symptomatology/adjustment disorder or anxiety/anxiety disorder. Charlson's Comorbidity Index could be calculated in $82 \%$ of patients and delivered a median index score of 2 (Q1: 1; Q3: 3) associated with a prediction of 10-year survival in these patients of 0.901 .

Comparing CHF patients with co-morbid conditions to CHF only patients, statistically significant differences $(p<0.001)$ were presented by the EQ-5D-5 $\mathrm{L}^{\mathrm{Tu}}$ items mobility, usual activities and pain/discomfort as well as by the EQ-5D-5 ${ }^{\mathrm{Tx}} \mathrm{VAS}$ and indices. More of problems and lower VAS and index values were shown in the CHF patients with co-morbid conditions. Comparing age quartiles, all EQ-5D-5L $\mathrm{L}^{\mathrm{Tm}}$ items as well as the EQ-5D-5 $\mathrm{L}^{\mathrm{mm}}$ VAS and indices presented statistically significant differences $(p<0.001)$ showing a deterioration of the patients' conditions by higher age.

\section{Construct validity}

The basic CFA model is presented in Fig. 1. The standardised regression coefficients of the EQ-5D-5L $\mathrm{L}^{\mathrm{ma}}$ items for the latent construct of HRQOL as well as the explained variances were almost identical when calculated with the ML and ADF methods. According to the local model fit statistics, the basic CFA model fit the data adequately. Only the explained variance of the item anxiety/depression revealed a value below the acceptable threshold. Reliability and the average proportion of variance were measured adequately by both methods; the global fit varied slightly (see Table 2). ANOVA results for the EQ-5D-5L $\mathrm{L}^{\mathrm{ma}} \mathrm{VAS}$ and the German and the British crosswalk index are presented in Fig. 2. Overall, strong associations were found between the EQ-5D-5 $\mathrm{L}^{\mathrm{mm}}$ parameters and the respective SF-36 measure of general health (VAS: partial eta-squared 53\%; German/British index $45 \% / 48 \%)$.

\section{Extended CFA}

In the extended CFA, a small effect was found for physical activity, a strong negative effect for psychosocial distress, and a negative correlation between physical activity and psychosocial distress (see Fig. 3). ANOVA of the EQ-5D$5 \mathrm{~L}^{\mathrm{Tm}} \mathrm{VAS}$, the German and the British crosswalk index, including a physical activity score and psychosocial distress classification, proved statistically significant and confirmed the influence of these factors on HRQOL in our CHF patients (see Fig. 4). 


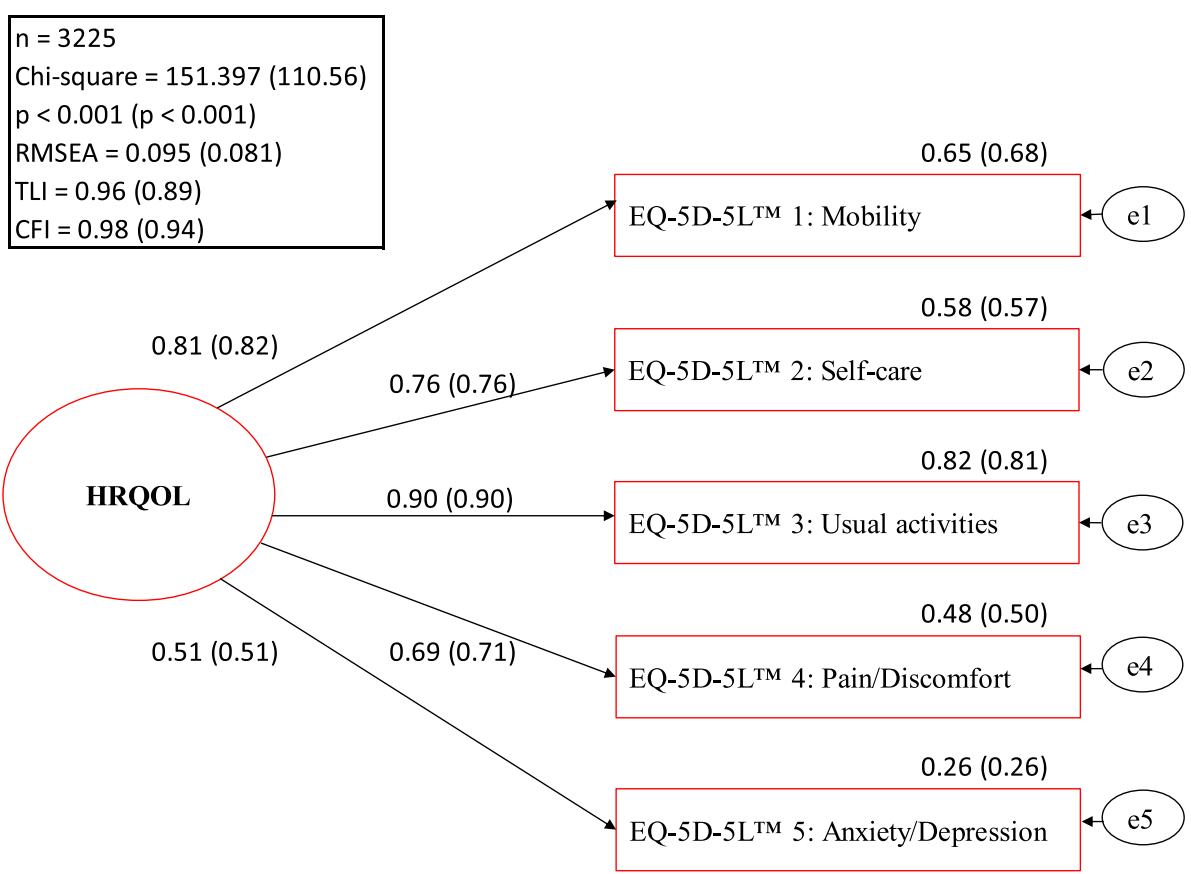

Fig. 1 Health-related quality of life (HRQOL) represented by the EQ-5D-5 $\mathrm{L}^{\mathrm{TM}}$ items. Basic measurement model of the latent construct of HRQOL with model fit and standardised parameter estimates calculated using the maximum likelihood and asymptotic distribution-free methods (in parentheses). E1 - e5 = residual variation

\section{Internal consistency reliability}

Cronbach's coefficient alpha was 0.856 , thus lying at the minimum threshold of 0.90 for individual use. A comparable value of 0.869 was obtained when experimentally removing the fourth item of anxiety/depression.

\section{Discriminative validity}

The comparison between the NYHA categories and all five EQ-5D-5L ${ }^{\mathrm{Tm}}$ items proved statistically significant $(p<0.001$; effects I1/I3/VAS/indices = moderate; I2/I4/ I5 = small; see Fig. 5). Few differences were found between NYHA I and II, the EQ-5D-5L $\mathrm{L}^{\mathrm{mm}}$ VAS, and the German and the British crosswalk index. However, changes did become apparent in stages III and IV (see Fig. 5).

\section{Discussion}

The EQ-5D-5L $\mathrm{L}^{\mathrm{Tm}}$ proved to be a reliable and valid method for measuring quality of life in CHF patients under primary care. The five questions of the short $\mathrm{EQ}$ $5 \mathrm{D}-5 \mathrm{~L}^{\mathrm{pu}}$ were completed by $n=3225$, i.e. $95 \%$, of the primary care patients of the observational RECODE-HF study; of these, $98 \%$ also answered the EQ-5D-5L ${ }^{\mathrm{mm}}$ VAS. In the present study, the EQ-5D-5 $\mathrm{L}^{\mathrm{m}}$ was found to be a suitable short generic instrument for assessing $\mathrm{CHF}$ patients in the primary care setting. Reasonable discriminative and construct validity was found for all parameters of the EQ-5D-5L $\mathrm{L}^{\mathrm{Tx}}$. More of problems represented by the EQ-5D-5L ${ }^{\mathrm{nt}}$ items mobility, usual activities and pain/discomfort and lower VAS and index values were shown in

Table 2 Measures of global fit, factor reliability and average proportion of variance for the basic CFA model and the CFA model adjusted for the variables physical activity and psychosocial distress

\begin{tabular}{|c|c|c|c|c|c|c|c|c|c|c|}
\hline & Valid $n$ & $\mathrm{Chi}^{2}$ & Df & $P$-value & $\mathrm{Chi}^{2} / \mathrm{Df}$ & TLI & $\mathrm{CFI}$ & RMSEA & Factor reliability & AVE \\
\hline Thresholds for model acceptance & & & & $>0.05$ & $<3$ & $\geq 0.90$ & $\geq 0.90$ & $\leq 0.08$ & $>0.60$ & $>0.50$ \\
\hline \multicolumn{11}{|l|}{ Basic model } \\
\hline Maximum likelihood method & 3225 & 151.40 & 5 & $<0.001$ & 30.28 & 0.96 & 0.98 & 0.095 & 0.87 & 0.58 \\
\hline Asymptotic distribution-free & 3225 & 110.56 & 5 & $<0.001$ & 22.11 & 0.89 & 0.94 & 0.081 & 0.87 & 0.59 \\
\hline \multicolumn{11}{|l|}{ Adjusted model } \\
\hline Maximum likelihood method & 3064 & 151.24 & 5 & $<0.001$ & 30.25 & 0.96 & 0.98 & 0.098 & 0.87 & 0.58 \\
\hline Asymptotic distribution-free & 3064 & 109.87 & 5 & $<0.001$ & 21.98 & 0.88 & 0.94 & 0.083 & 0.87 & 0.59 \\
\hline
\end{tabular}

CFA, confirmatory factor analysis; Df, degrees of freedom; TLI, Tucker Lewis Index; CFI, Comparative Fit Index; RMSEA, root mean square error of approximation; AVE, average proportion of variance measured; for thresholds see Schermelleh-Engel, Moosbrugger and Müller 2003; Kline 2011; Hooper, Coughlan and Mullen 2008 [22, 25, 26] 

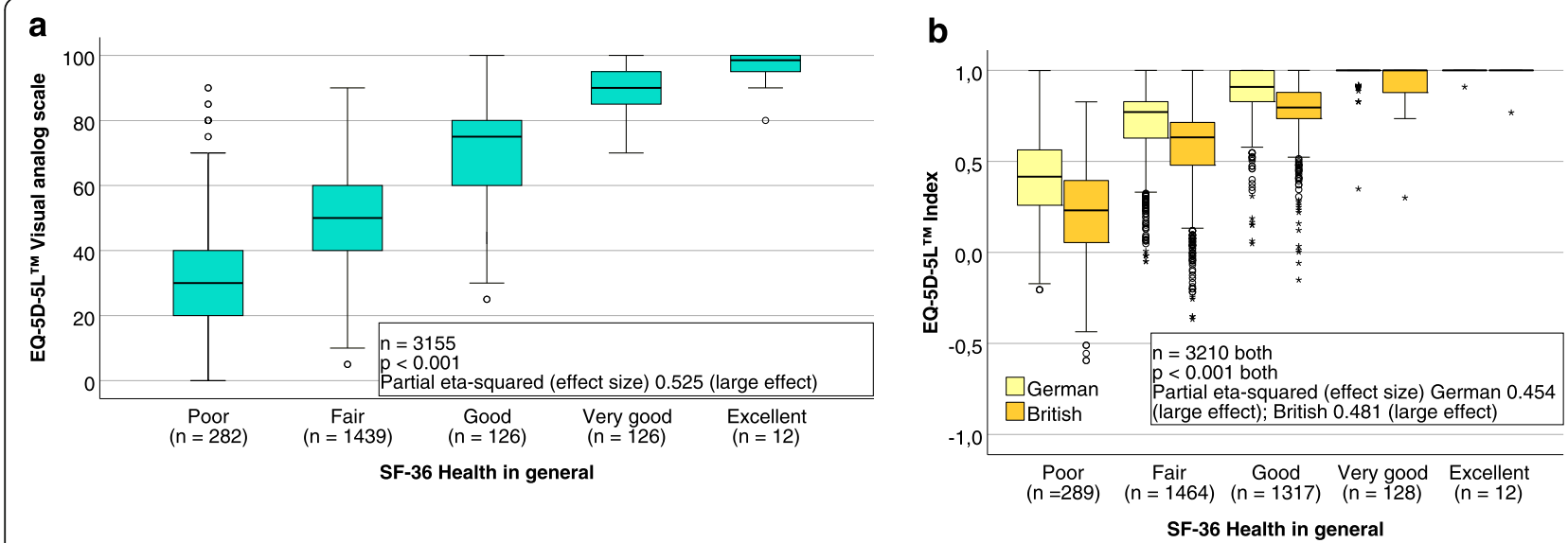

Fig. 2 EQ-5D-5 $L^{\text {TM }}$ parameters and general health status. The association of the EQ-5D-5 $L^{\text {TM }} V A S(\mathbf{a})$, and the German and the British crosswalk index of the EQ-5D-5 $\mathrm{L}^{\mathrm{TM}}$ (b) with the SF-36 measure of general health

the CHF patients with co-morbid conditions compared to CHF only patients, and also a higher age predicted deterioration shown by all EQ-5D-5L ${ }^{\mathrm{Tm}}$ parameters. Thus giving evidence on the differences in the EQ-5D-5 $\mathrm{L}^{\mathrm{Tu}}$ parameters by CHF patients' conditions. CHF patients are usually older patients and often have several comorbidities and risk factors, and typically the quality of life continually decreases as the severity of the disease increases [5]. Disease management guidelines also state that pathophysiological mechanisms of chronic heart failure and non-cardiac changes, e.g. musculoskeletal changes due to reduced blood flow, together explain the occurrence of exercise and stress intolerance, fatigue and lethargy in CHF patients $[5,6]$. Only for the question on anxiety/depression was there an explained variance below the threshold in our analysis, as in the analyses by Clouth et al. with the former EQ-5D-3L ${ }^{\mathrm{Tm}}$ in CHF patients [16]. Clouth et al. concluded that this resulted from the combination of two different definitions in the item anxiety/depression [16]. We agree and suggest, moreover, that due to the influence of psychosocial distress on other, physical areas, a depressive symptomatology is reflected in the response to all items. Physical activity and psychosocial distress were confirmed as influencing HRQOL in our research when measured with the EQ-5D-5L $\mathrm{L}^{\mathrm{mm}}$ in CHF patients. In August 2017 the National Institute for Health and Care Excellence (NICE) in the UK released a statement on the EQ-5D$5 \mathrm{~L}^{\mathrm{Tm}}$, recommending use of the five-level version of the

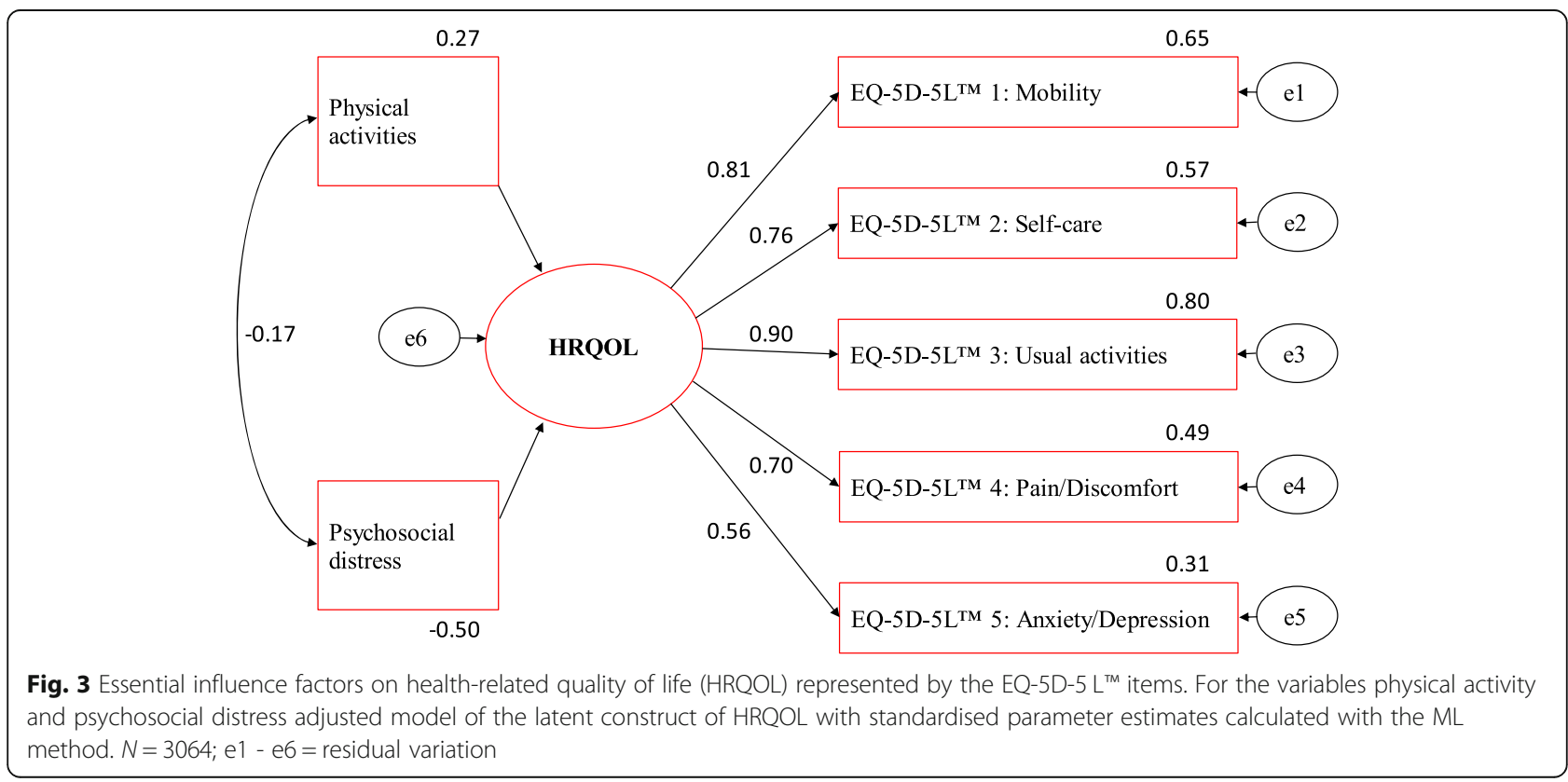




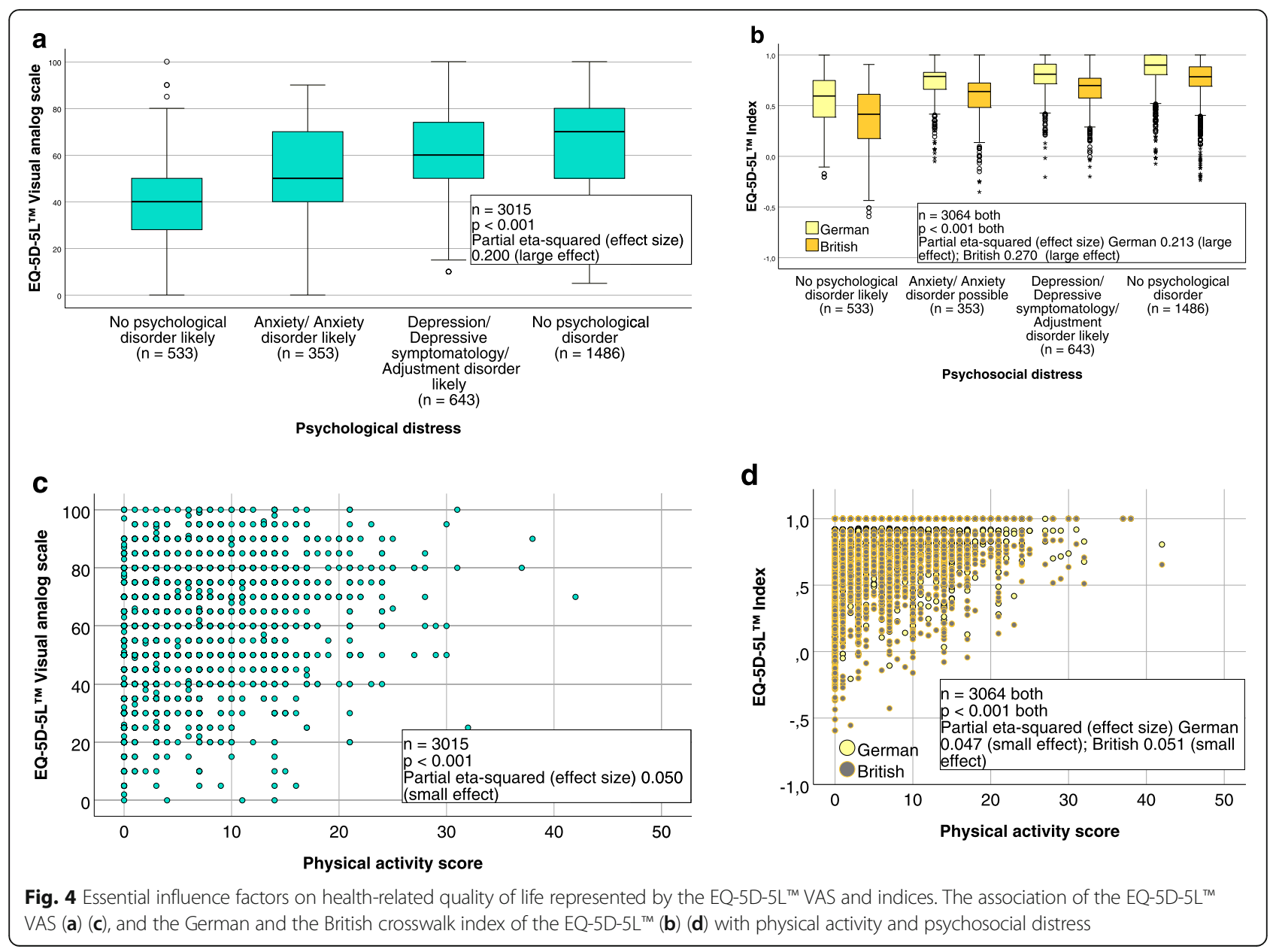

EQ-5D ${ }^{\circ}$ for collecting data on HRQOL $[41,42]$. We present values related to validity here that are necessary before widespread use of the tool in CHF patients.

Jaarsma et al. concluded in their qualitative study in CHF patients that psychosocial adaptation to disease could be enhanced by improving the ability to care for oneself [10]. As we have shown in Fig. 4, the disease burden is high in CHF patients with NYHA class III and IV. The degree to which self-care is restricted, as reflected by item 2 of the EQ-5D-5L $\mathrm{L}^{\mathrm{m}}$, was found to be an influential factor in CHF patients, and is assumed to be relevant to everyday life. Our findings support the conclusion of Stamp et al. 2014, namely that maintaining autonomy in patients with heart failure is of great importance [12].

Hoekstra et al. 2012 surmised that most CHF studies would rather use a disease-specific questionnaire to assess quality of life [13]. This could take the form of a specific application in clinical research, whereas in primary care there may be different priorities. Jaarsma et al. concluded that in clinical practice CHF patients cannot be easily compared to those in clinical trials or those undergoing transplant evaluation given that their functional capabilities are more greatly impaired [10].
However, according to McDonald et al. 2017 and the aspect of personalised care as the ideal future scenario, including high anticipated costs, use of a short generic questionnaire would seem more convenient given that time is limited in primary care consultations. When taking the medical history of a CHF patient, it is important to classify not only the heart failure burden but also, as this research highlights, activities of daily living and selfcare, which is entirely feasible with the EQ-5D-5 $\mathrm{L}^{\mathrm{mm}}$. This is crucial in CHF patients with a high disease burden. Brunner-La Rocca et al. demonstrated that patients with a higher disease burden were more willing to trade survival time for quality of life [8]. Our research with the generic EQ-5D-5 $\mathrm{L}^{\mathrm{mi}}$ clearly distinguished CHF patients with severe heart failure of NYHA class III and IV from patients in a lower NYHA class with respect to HRQOL and CHF. Due to increased pain and physical discomfort as well as limited autonomy, HRQOL was severely limited in CHF patients with severe heart failure. This emphasises the special clinical relevance of these aspects.

To the best of our knowledge, our research is the first to validate the EQ-5D-5 $\mathrm{L}^{\mathrm{m}}$ for use in CHF patients. It can be assumed to offer additional benefit in the European 

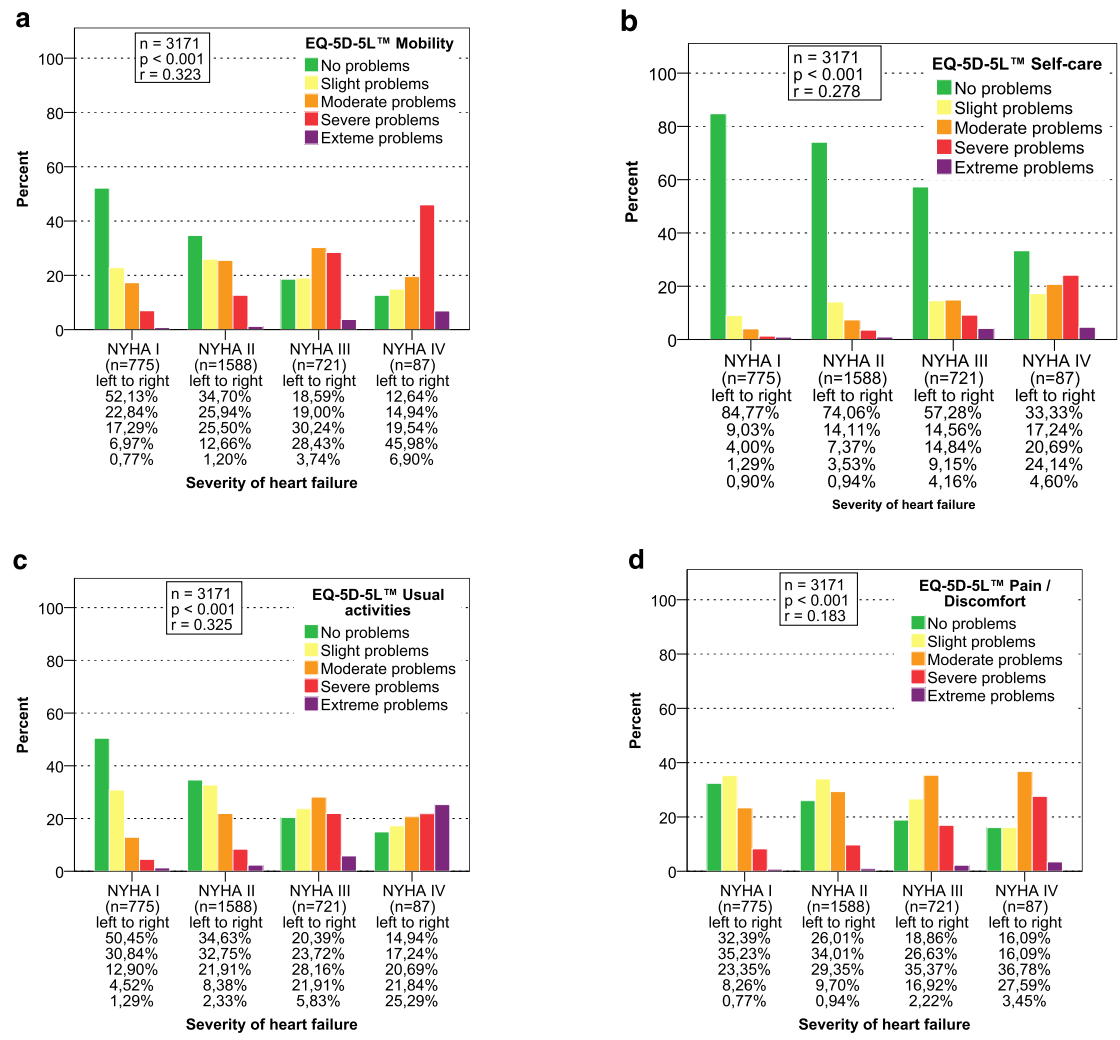

e
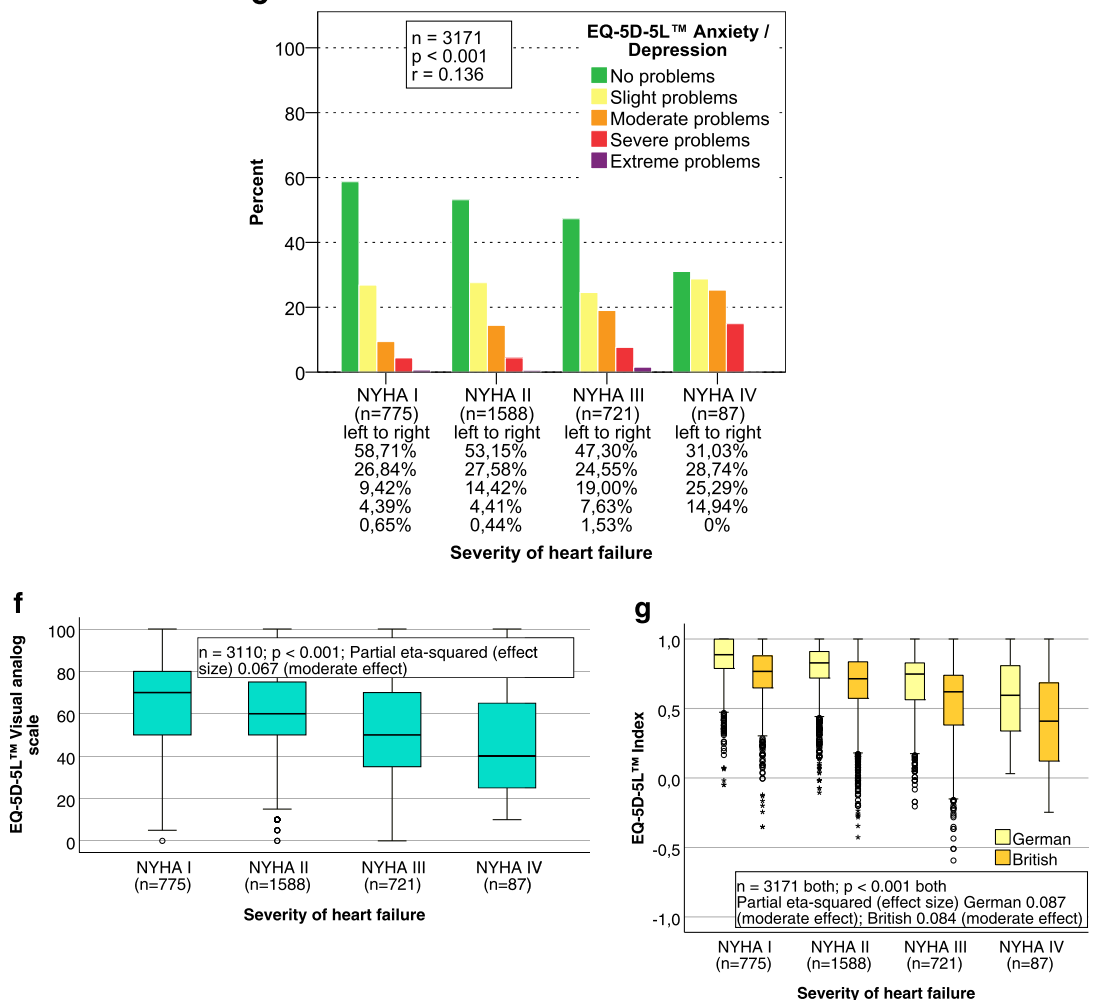

Fig. 5 Discriminative ability indicated by the severity of heart failure according to the NYHA classes. The discriminative ability of the five

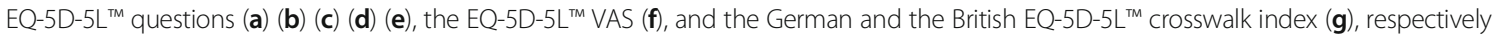


context, not least because validation of the British version of the EQ-5D-5L $\mathrm{L}^{\mathrm{Tm}}$ for CHF patients is still pending. The extent of the overall burden of multimorbidity was comparable to the study of CHF patients in Italy by Gasperoni et al., which revealed a median Charlson Comorbidity Index score of 2 and identical quartiles $(1 ; 3)$ to the Italian study patients who were hospitalised only once. Due to the shortness of the questionnaire its use in the primary care setting (coupled with patient decision management, and talking about the patient's quality of life) may provide the impetus for discussion of the patient's HRQOL. It could motivate patients to become more actively involved in improving their quality of life.

\section{Strengths and limitations}

This is the first time that the EQ-5D-5 $\mathrm{L}^{\mathrm{ma}}$ has been validated in a large sample of CHF patients in Germany.

One limitation of the RECODE-HF study is that patients were not primarily recruited with the aim of validating the EQ-5D. As described in the study protocol, enrolment of patients with symptoms of anxiety/depression was prioritised [43]. However, the proportion of $28 \%$ CHF patients with possible/probable psychosocial distress is similar to the 30\% depressive CHF patients in the German KCCQ validation study by Steinbüchel [44]. Similarly, in another German primary care study Scherer et al. reported a $29 \%$ increase in anxiety/depression in CHF patients [45]. Therefore, we assume that our CHF patient population is a representative sample and have described this sample thoroughly to allow for comparison of our results against other studies. For instance, the worsening of the CHF patients' conditions by co-morbid conditions and age was shown by EQ-5D-5L $\mathrm{L}^{\mathrm{Tx}}$ items, the EQ VAS and indices, and also confirmed the representability of the sample [5].

Given that CHF is highly complex, our validation analyses did not include other factors that could affect HRQOL, such as age, co-medication, duration of disease, number of hospitalisations and patient adherence to therapeutic interventions. Whereas some measurement analyses with the EQ VAS of the EQ-5D-5 $\mathrm{L}^{\mathrm{ma}}$ have been repeated using RECODE-HF follow-up data published recently [46], further research into the test-retest reliability of the EQ-5D-5 $\mathrm{L}^{\mathrm{mm}}$ in CHF patients is still ongoing.

\section{Conclusion}

The instrument is valid and reliable. This research into the EQ-5D-5L $\mathrm{L}^{\mathrm{Tm}}$ in CHF patients has shown that there is a strong correlation between HRQOL and health limitations that affect mobility and activities of daily living. They play a key role, especially in CHF patients with permanent health stress at advanced stages of the disease. In summary, it can be assumed that the very short generic German EQ-5D-5L ${ }^{\mathrm{mm}}$ is a suitable tool for assessing HRQOL in CHF patients in the primary care setting.

\section{Abbreviations}

ADF: Asymptotic distribution-free; ANOVA: Analyses of variance;

CFA: Confirmatory factor analysis; CFI: Comparative Fit Index; CHF: Chronic heart failure; EQ-5D: Standardized instrument developed by the EuroQol Group as a measure of health-related quality of life; EQ-5D-5L: 5-level EQ-5D version; GP: General practitioner; HADS-A: Hospital Anxiety Scale; HADSD: Hospital Depression Scale; HRQOL: Health-related quality of life; KCCQ: Kansas City Cardiomyopathy Questionnaire; ML: Maximum likelihood; NYHA: New York Heart Association; PHQ-9: Patient Health Questionnaire depression subscale; PROMIS ${ }^{\oplus}$ : Patient-Reported Outcomes Measurement Information System; RMSEA: root mean square error of approximation; SD: Standard deviation; TLI: Tucker-Lewis Index; VAS: Visual analogue scale

\section{Acknowledgements}

We wish to thank Agata Kazek and Anja Rakebrandt for their contribution to data acquisition and Beverley Taylor-Jones for critical revision of the Englishlanguage manuscript.

The manuscript includes content from the doctoral thesis of SB, accessible at http://ediss.sub.uni-hamburg.de/volltexte/2017/8875/ (German). Some of the results in this manuscript were presented by SB as a poster at the $2017 \mathrm{EbM}$ Congress in Hamburg, Germany, accessible at http://www.egms.de/static/en/ meetings/ebm2017/17ebm055.shtml (German).

\section{Authors' contributions}

SB planned, evaluated and interpreted the statistical analyses and wrote the manuscript. SB also made substantial contributions to the conception, design and analyses of the RECODE-HF study. AD made substantial contributions to the analyses and interpretation of data. ME coordinated the RECODE-HF study in addition to contributing significantly to its conception and design. EB made substantial contributions to the conception and design of the RECODE-HF study. MS procured the funding and designed the RECODE-HF study, and acted as principal investigator; he was first supervisor for the doctoral thesis written by SB. All authors read the manuscript critically and approved the final version.

\section{Funding}

This work was supported by the German Federal Ministry of Education and Research [grant numbers 01GY1150 and 01E01004]. The funders had no role in the design or conduct of the study; in the collection, analysis, and interpretation of data; or in the preparation or approval of the manuscript.

\section{Availability of data and materials}

The data from this study is not available for public use, as the data is owned by the RECODE-HF Study Group and the authors are not allowed to share this information with third parties.

\section{Ethics approval and consent to participate}

The study complies with the Declaration of Helsinki. The RECODE-HF study was approved by all local ethics committees (Medical Association of Hamburg, Approval No. PV3889; Ethics Committee of the Medical Faculty of the University of Würzburg, Approval No. 125/12, Ethics Committee at the University of Göttingen Medical Center, Approval No. 19/8/11). All study participants gave written informed consent before participating in the study.

\section{Consent for publication}

Not applicable.

\section{Competing interests}

$\mathrm{SB}$ received fees as a part-time lecturer/statistical consultant from Asklepios Medical School $\mathrm{GmbH}$. All other authors declare that they have no financial conflicts of interest. Non-financial conflicts of interest: ME is a member of the German College of General Practitioners and Family Physicians. MS is VicePresident of the German College of General Practitioners and Family Physicians. EB is employed by a Swiss health insurance company. All other authors declare that they have no non-financial conflicts of interest.

\section{Author details}

'Department of General Practice / Primary Care, Center for Psychosocial Medicine, University Medical Center Hamburg-Eppendorf, Germany, Martinistraße 52, 20246 Hamburg, Germany. ${ }^{2}$ Department of Medical Biometry and Epidemiology, University Medical Center Hamburg-Eppendorf, Germany, Martinistraße 52, 20246 Hamburg, Germany. 
Received: 27 March 2019 Accepted: 13 September 2019 Published online: 06 November 2019

\section{References}

1. Sturm HB, van Gilst WH, Swedberg K, Hobbs FR, Haaijer-Ruskamp FM. Heart failure guidelines and prescribing in primary care across Europe. BMC Health Serv Res. 2005;5. https://doi.org/10.1186/1472-6963-5-57.

2. Muntwyler J, Cohen-Solal A, Freemantle N, Eastaugh J, Cleland JG, Follath F. Relation of sex, age and concomitant diseases to drug prescription for heart failure in primary care in Europe. Eur J Heart Fail. 2004;6:663-8.

3. McDonald MA, Ashley EA, Fedak PWM, Hawkins N, Januzzi JL, McMurray JJV, et al. Mind the gap: current challenges and future state of heart failure care. Can J Cardiol. 2017;33:1434-49.

4. Ponikowski P, Voors AA, Anker SD, Bueno H, Cleland JGF, Coats AJS, et al. 2016 ESC guidelines for the diagnosis and treatment of acute and chronic heart failure:- web addenda. The task force for the diagnosis and treatment of acute and chronic heart failure of the European Society of Cardiology (ESC). Developed with the special contribution of the heart failure association (HFA) of the ESC. Eur J Heart Fail. 2016;18: 891-975.

5. Bundesärztekammer (BÄK), Kassenärztliche Bundesvereinigung (KBV), Arbeitsgemeinschaft der Wissenschaftlichen Medizinischen Fachgesellschaften (AWMF). Nationale VersorgungsLeitlinie Chronische Herzinsuffizienz. 2009. http://www.leitlinien.de/mdb/downloads/nvl/ herzinsuffizienz/herzinsuffizienz-2aufl-vers2-lang.pdf. Accessed 1 Nov 2017.

6. Hunt SA, Baker DW, Chin MH, Cinquegrani MP, Feldman AM, Francis GS, et al. ACC/AHA guidelines for the evaluation and management of chronic heart failure in the adult: executive summary: A report of the american college of cardiology/american heart association task force on practice guidelines (committee to revise the 1995 guidelines for the evaluation and management of heart failure) developed in collaboration with the international society for heart and lung transplantation endorsed by the heart failure society of america. J Am Coll Cardiol. 2001;38:2101-13.

7. Gasperoni F, leva F, Barbati G, Scagnetto A, lorio A, Sinagra G, et al. Multistate modelling of heart failure care path: a population-based investigation from Italy. PLoS One. 2017;12:e0179176.

8. Brunner-La Rocca H-P, Rickenbacher P, Muzzarelli S, Schindler R, Maeder MT Jeker U, et al. End-of-life preferences of elderly patients with chronic heart failure. Eur Heart J. 2012:33:752-9.

9. Tschöpe C, Birner C, Böhm M, Bruder O, Frantz S, Luchner A, et al. Heart failure with preserved ejection fraction: current management and future strategies. Clin Res Cardiol. 2018;107:1-19.

10. Jaarsma T, Halfens R, Abu-Saad HH, Dracup K, Stappers J, Ree J. Quality of life in older patients with systolic and diastolic heart failure. Eur J Heart Fail. 1999;1:151-60

11. Whellan DJ, O'Connor CM, Lee KL, Keteyian SJ, Cooper LS, Ellis SJ, et al. Heart failure and a controlled trial investigating outcomes of exercise TraiNing (HF-ACTION): design and rationale. Am Heart J. 2007;153:201-11.

12. Stamp KD, Dunbar SB, Clark PC, Reilly CM, Gary RA, Higgins M, et al. Family context influences psychological outcomes of depressive symptoms and emotional quality of life in patients with heart failure. J Cardiovasc Nurs. 2014;29:517-27.

13. Hoekstra T, Jaarsma T, Veldhuisen DJ, Hillege HL, Sanderman R, LesmanLeegte I. Quality of life and survival in patients with heart failure. Eur J Heart Fail. 2013;15:94-102.

14. Rector TS, Carson PE, Anand IS, McMurray JJ, Zile MR, McKelvie RS, et al. Assessment of long-term effects of Irbesartan on heart failure with preserved ejection fraction as measured by the Minnesota living with heart failure questionnaire in the Irbesartan in heart failure with preserved systolic function (I-PRESERVE) trial. Circ Heart Fail. 2012;5:217.

15. The EuroQol Group. EQ-5D-5L | About. 2017. https://euroqol.org/eq-5dinstruments/eq-5d-5l-about/. Accessed 26 Oct 2017.

16. Clouth J, Brähler E, Schmidt P, Kohlmann T. Testing construct validity of EQ$5 \mathrm{D}$ by Confirmatory Factor Analysis and Structural Equation Modeling (SEM). In: Baveno 2008 EuroQol Proceedings. 2008. http://eq-5dpublications. euroqol.org/download?id=0_53699\&fileld=54114. Accessed 24 Aug 2016.

17. Robert Koch-Institut, editor. Gesundheit in Deutschland. Gesundheitsberichterstattung des Bundes. Gemeinsam getragen von RKI und Destatis. Berlin: Robert Koch-Institut; 2015.
18. Herdman M, Gudex C, Lloyd A, Janssen MF, Kind P, Parkin D, et al. Development and preliminary testing of the new five-level version of EQ-5D (EQ-5D-5L). Qual Life Res. 2011;20:1727-36.

19. EuroQol Group. EQ-5D-5L. FAQs. http://euroqol.org/eq-5d-instruments/eq-5 d-5l-about/faqs/. Accessed 16 Jan 2018.

20. van Hout B, Janssen MF, Feng Y-S, Kohlmann T, Busschbach J, Golicki D, et al. Interim scoring for the EQ-5D-5L: mapping the EQ-5D-5L to EQ-5D-3L value sets. Value Health. 2012;15:708-15.

21. Charlson ME, Pompei P, Ales KL, MacKenzie CR. A new method of classifying prognostic comorbidity in longitudinal studies: development and validation. J Chronic Dis. 1987;40. https://doi.org/10.1016/0021-9681(87)90171-8.

22. Schermelleh-Engel $\mathrm{K}$, Moosbrugger $\mathrm{H}$, Müller $\mathrm{H}$. Evaluating the fit of structural equation models: test of significance and descriptive goodnessof-fit measures. Methods Psychol Res - Online. 2003;8(2):23-74.

23. Olsson UH, Foss T, Troye SV, Howell RD. The performance of ML, GLS, and WLS estimation in structural equation modeling under conditions of misspecification and nonnormality. Struct Equ Model Multidiscip J. 2000;7: 557-95

24. Wirtz M. Einführung in die Analyse von Strukturgleichungsmodellen mit AMOS; 2016.

25. Kline R. Principles and practice of structural equation modeling. 3rd ed. New York: Guilford Publications; 2011.

26. Hooper D, Coughlan J, Mullen M. Structural equation Modelling: guidelines for determining model fit. Electron J Bus Res Methods. 2008;6(1):53-60.

27. Sousa KH, Kwok O-M. Putting Wilson and Cleary to the test: analysis of a HRQOL conceptual model using structural equation modeling. Qual Life Res. 2006:15:725-37.

28. Tran U. Effektstärken und deren Bedeutung für die klinische Forschung. 2011. http://ppcms.univie.ac.at/uploads/media/Effektstaerken.pdf. Accessed 29 Jul 2017.

29. Richardson JTE. Eta squared and partial eta squared as measures of effect size in educational research. Educ Res Rev. 2011:6:135-47.

30. Salazar A, Dueñas M, Fernandez-Palacin F, Failde I. Factors related to the evolution of health related quality of life in coronary patients. A longitudinal approach using weighted generalized estimating equations with missing data. Int J Cardiol. 2016:223:940-6.

31. Scherer M, Himmel W, Stanske B, Scherer F, Koschack J, Kochen MM, et al. Psychological distress in primary care patients with heart failure: a longitudinal study. Br J Gen Pract. 2007:57:801.

32. Eisele M, Rakebrandt A, Boczor S, Kazek A, Pohontsch N, Okolo-Kulak M, et al. Factors associated with general practitioners' awareness of depression in primary care patients with heart failure: baseline-results from the observational RECODE-HF study. BMC Fam Pract. 2017;18. https://doi.org/10. 1186/s12875-017-0641-1.

33. Spitzer RL, Kroenke K, Williams JB. Validation and utility of a self-report version of PRIME-MD: the PHQ primary care study. Primary Care Evaluation of Mental Disorders. Patient health questionnaire. JAMA. 1999;282. https://doi.org/10.1001/jama.282.18.1737

34. Kroenke K, Spitzer RL, Williams JB. The PHQ-9: validity of a brief depression severity measure. J Gen Intern Med. 2001;16. https://doi.org/10.1046/j.15251497.2001.016009606x

35. Löwe B, Gräfe K, Zipfel S, Witte S, Loerch B, Herzog W. Diagnosing ICD-10 depressive episodes: superior criterion validity of the patient health questionnaire. Psychother Psychosom. 2004;73. https://doi.org/10.1159/000080393.

36. Bjelland I, Dahl AA, Haug TT, Neckelmann D. The validity of the hospital anxiety and depression scale: an updated literature review. J Psychosom Res. 2002;52:69-77.

37. Herrmann-Lingen C, Buss U, Snaith R. HADS-D - hospital anxiety and depression scale - deutsche version: deutsche adaptation der Hospital anxiety and depression scale (HADS). Bern: Huber; 2005.

38. Pilkonis PA, Choi SW, Reise SP, Stover AM, Riley WT, Cella D. Item banks for measuring emotional distress from the patient-reported outcomes measurement information system (PROMIS ${ }^{\oplus}$ ): depression, anxiety, and anger Assessment. 2011;18. https://doi.org/10.1177/1073191111411667.

39. Choi SW, Reise SP, Pilkonis PA, Hays RD, Cella D. Efficiency of static and computer adaptive short forms compared to full-length measures of depressive symptoms. Qual Life Res. 2010;19. https://doi.org/10.1007/ s11136-009-9560-5.

40. Frost MH, Reeve BB, Liepa AM, Stauffer JW, Hays RD. What is sufficient evidence for the reliability and validity of patient-reported outcome measures? Value Health. 2007;10:594-105. 
41. National Institute for Health and Care Excellence. Position statement on use of the EQ-5D-5L valuation set. https://www.nice.org.uk/Media/Default/ About/what-we-do/NICE-guidance/NICE-technology-appraisal-guidance/eq5 d5I_nice_position_statement.pdf. Accessed 23 Oct 2017.

42. EuroQol Group. NICE position statement on the EQ-5D-5L. 2017. https:// eurogol.org/nice-position-statement-on-the-eq-5d-51/. Accessed 23 Oct 2017.

43. Eisele M, Blozik E, Störk S, Träder J-M, Herrmann-Lingen C, Scherer M. Recognition of depression and anxiety and their association with quality of life, hospitalization and mortality in primary care patients with heart failure - study protocol of a longitudinal observation study. BMC Fam Pract. 2013;14:180.

44. Steinbüchel T. Psychometrische Prüfung der deutschen Version des Kansas City Cardiomyopathy Questionnaire (KCCQ) - Unter Berücksichtigung des Einflusses einer komobiden Depression auf die Validität. Albert-LudwigsUniversität Freiburg, Wirtschafts- und Verhaltenswissenschaftliche Fakultät unter Beteiligung des Instituts für Psychologie; 2005. https://freidok.unifreiburg.de/data/2512. Accessed 2 Feb 2017.

45. Scherer M, Stanske B, Wetzel D, Koschack J, Kochen MM, Herrmann-Lingen C. Psychosocial co-symptoms in primary care patients with heart failure. Herz. 2006;31:347-54.

46. Eisele M, Boczor S, Rakebrandt A, Blozik E, Träder J-M, Störk S, et al. General practitioners' awareness of depressive symptomatology is not associated with quality of life in heart failure patients - cross-sectional results of the observational RECODE-HF study. BMC Fam Pract. 2017;18:100.

\section{Publisher's Note}

Springer Nature remains neutral with regard to jurisdictional claims in published maps and institutional affiliations.

Ready to submit your research? Choose BMC and benefit from:

- fast, convenient online submission

- thorough peer review by experienced researchers in your field

- rapid publication on acceptance

- support for research data, including large and complex data types

- gold Open Access which fosters wider collaboration and increased citations

- maximum visibility for your research: over $100 \mathrm{M}$ website views per year

At $\mathrm{BMC}$, research is always in progress.

Learn more biomedcentral.com/submissions 